\title{
Functional index for hand osteoarthritis (FIHOA) is associated with pain, muscle strength, and EQ-5D in hand osteoarthritis
}

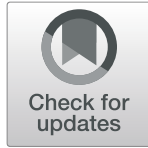

\author{
Seong-Kyu Kim ${ }^{*}$ D, Ui Hong Jung and Jung-Yoon Choe
}

\begin{abstract}
Background: This study identified whether Functional Index for Hand Osteoarthritis (FIHOA) is associated with pain, hand muscle strength, health-related quality of life, and radiographic severity in hand osteoarthritis (OA).

Methods: We consecutively recruited 95 patients with hand OA. The FIHOA was used to assess questionnairebased physical function in hand OA. Health-related quality of life was evaluated using EuroQol-5 dimension (EQ-5D). Radiographic changes of hand joints were measured by Kellgren-Lawrence (K-L) grade, which was determined based on total radiographic severity score and number of affected joints. Other measures included patient's visual analogue scale (VAS) score for pain and performance-based function indexes such as grip and pinch strength. Statistical analysis was performed using Mann-Whitney U test, Spearman's correlation analysis, and multivariate logistic regression analysis.

Results: FIHOA score was negatively associated with grip and pinch hand strength and EQ-5D and positively correlated to VAS pain $(p<0.05$ for all). There were significant differences of grip and pinch strength, VAS pain, EQ$5 \mathrm{D}$ index, and EQ-VAS between two FIHOA groups ( $\leq 4$ vs. $>4)(p<0.05$ for all). Multivariate logistic regression analysis showed that higher FIHOA score (FIHOA $>4)$ was related with increased VAS pain and with lower EQ-5D index ( $p=0.008$ and $p=0.013$, respectively). There was no association between FIHOA score and measures of total radiographic severity score and number of affected joints.
\end{abstract}

Conclusion: This study observes that FIHOA score is associated with patient-reported VAS pain, hand muscle strength indexes, and EQ-5D but not radiographic severity in hand OA.

Keywords: Osteoarthritis, Hand, FIHOA, EQ-5D, VAS, Kellgren-Lawrence grade

\section{Background}

Hand osteoarthritis $(\mathrm{OA})$ is a prevalent degenerative disease that leads to pain, joint deformity, functional disability, and impaired quality of life $[1,2]$. The clinical phenotypes of hand $\mathrm{OA}$ seem to be heterogeneous according to number and pattern of joint involvement. The Outcome Measures in Rheumatology (OMERACT) and the Osteoarthritis Research Society International (OARSI) Task Force on Clinical Trials Guidelines have

\footnotetext{
* Correspondence: kimsk714@cu.ac.kr

Division of Rheumatology, Department of Internal Medicine, Catholic University of Daegu School of Medicine, 33, Duryugongwon-ro 17-gil, Nam-gu, Daegu 42472, Republic of Korea
}

been frequently used in clinical trials [3, 4]. For assessment of physical function based on a questionnaire for hand $\mathrm{OA}$, outcome measures from the pain subscale of the Australian/Canadian (AUSCAN) Index [5], the Cochin hand functional disability scale [6], and the Functional Index for Hand Osteoarthritis (FIHOA) [7] have been used in clinical trials and have been shown to be valid, reliable, and relevant.

The FIHOA is a unidimensional questionnaire that is structurally different from the AUSCAN index, which measures pain, stiffness, and function dimensions $[7,8]$. A case-control study revealed that FIHOA score was gradually increased as the severity of hand OA increased [9].

(c) The Author(s). 2021 Open Access This article is licensed under a Creative Commons Attribution 4.0 International License, which permits use, sharing, adaptation, distribution and reproduction in any medium or format, as long as you give appropriate credit to the original author(s) and the source, provide a link to the Creative Commons licence, and indicate if changes were made. The images or other third party material in this article are included in the article's Creative Commons licence, unless indicated otherwise in a credit line to the material. If material is not included in the article's Creative Commons licence and your intended use is not permitted by statutory regulation or exceeds the permitted use, you will need to obtain permission directly from the copyright holder. To view a copy of this licence, visit http://creativecommons.org/licenses/by/4.0/. 
In a study that analyzed 18 patients with hand OA, FIHOA score was found to be correlated with the degree of radiological damage, but not synovial inflammation based on magnetic resonance image (MRI) [10]. Compatible with previous studies $[7,8]$, Koutroumpas et al. confirmed significant association between FIHOA and clinical assessment for erosive hand OA [11]. In addition, FIHOA was noted to related with MRI-defined bone attrition in 77 female patients with hand OA [12]. However, there is a lack of research data regarding FIHOA score and hand muscle strength or quality of life in hand OA. The main aim of this study is to determine association of FIHOAbased functional status with pain, grip and pinch strength, quality of life, and radiographic severity in hand OA.

\section{Subjects and methods Study population}

A total of 95 patients with Korean hand OA that met the American College of Rheumatology (ACR) classification criteria was recruited from the Rheumatology Clinic and enrolled in this study from February 2019 to January 2020 [13]. All patients showed radiographic changes at more than one of both hand joints assessed according to the Kellgren-Lawrence (K-L) grading system [14]. This study excluded patients diagnosed with rheumatoid arthritis, systemic lupus erythematosus, psoriatic arthritis, and gouty arthritis.

\section{Clinical information}

Demographic data were age (years), sex, body mass index $\left(\mathrm{BMI}, \mathrm{kg} / \mathrm{m}^{2}\right)$, systolic blood pressure (SBP, $\mathrm{mmHg}$ ), diastolic blood pressure (DBP, $\mathrm{mmHg}$ ), and symptom duration (months) at time of enrollment. Acute phase reactants, such as erythrocyte sediment rate (ESR) and C-reactive protein (CRP), were measured. Pain was scored using a $100 \mathrm{~mm}$ Visual Analogue Scale (VAS). The Functional Index for Hand Osteoarthritis (FIHOA) questionnaire was assessed for hand physical function scores from 0 to 30 and was composed of 10 doctor-administered questions with semi-quantitative assessment on a 4-point Likert scale ranging from 0 to 3 $[7,8]$. This study used a Korean version of the FIHOA, which was validated in Korean patients with hand OA [15]. FIHOA scores were divided into two groups based on four points (FIHOA $\leq 4$ vs. FIHOA $>4$ ) according to classification by an earlier study [7].

\section{EuroQol-5 dimension (EQ-5D) measurement}

The Korean version of EQ-5D is a tool to measure health-related quality of life (HRQOL) [16]. The EQ-5D consists of the EQ-5D index and the EQ-VAS. The EQ$5 \mathrm{D}$ index consists of five questions that ask about the current state of health as mobility, self-care, usual activities, pain/discomfort, and anxiety/depression.

\section{Radiological assessment}

Total radiographic severity scores were the sum of Kellgren-Lawrence (K-L) grade scores at a total of 20 joints such as 2nd - 5th distal interphalangeal (DIP) joints, 2nd -5 th proximal interphalangeal (PIP) joints, thumb interphalangeal (IP) joint, and first carpometacarpal joint of both hands, which ranged from grade 0 to grade 80 . The number of affected joints with any kind of radiologic change was calculated for each subject according to the K-L grading system. A single rheumatologist completing a training program (UH Jung) provided radiographic digital images of hand joints from the Korean College of Rheumatology.

\section{Muscle strength measurement}

Measurement for grip strength in both hands was performed with arms and elbows at right angles using a dynamometer (Jamar Hydraulic Hand Dynamometer, Nottinghamshire, UK). Pinch strength for the first and second fingers was measured by a pinch gauge (B\&L Engineering, Tustin, CA, USA). The mean values for grip strength and pinch strength were presented after measurements on both hands.

\section{Statistical analysis}

Data are described as median (interquartile range [IQR]) for continuous variables and number (percentage [\%]) for nominal variables. The Shapiro-Wilk test was applied to test normality and showed a non-normal distribution. The correlations between FIHOA score and clinical and radiographic variables were measured by Spearman's correlation coefficient. The differences of variables between FIHOA $\leq 4$ and FIHOA $>4$ were calculated by Mann-Whitney $U$ test. Multivariate logistic regression analysis was performed to identify clinical and radiographic variables related to higher FIHOA score $>4$ along with the odds ratio (OR) and 95\% confidence interval (CI). A $P$ value less than 0.5 was considered statistically significant. Statistical analyses were performed by IBM SPSS Statistics 19.0 (IBM Corp., Armonk, NY, USA).

\section{Results \\ Baseline characteristics}

Baseline characteristics of enrolled subjects are described in Table 1. The median age was 60.0 years (IQR 54.0$66.0)$, and most subjects were female $(n=90,94.7 \%)$. The average values of grip strength and pinch strength were 20.0 (IQR 16.5-24.5) and 5.7 (IQR 4.8-6.5), respectively, and the median score of FIHOA was 65.0 (IQR 50.0-80.0). Radiographic changes were measured as 6.0 (IQR 2.0-18.0) for total radiographic severity score and 5.0 (IQR 2.0-9.0) for affected joint count. 
Table 1 Baseline characteristics of enrolled subjects

\begin{tabular}{|c|c|}
\hline Variables & Results \\
\hline Age (year) & $60.0(54.0-66.0)$ \\
\hline Sex, female $(n, \%)$ & $90(94.7)$ \\
\hline Symptom duration (month) & $6.0(1.0-73.0)$ \\
\hline BMI $\left(\mathrm{kg} / \mathrm{m}^{2}\right)$ & $23.4(21.5-24.9)$ \\
\hline SBP $(\mathrm{mmHg})$ & $127.0(115.0-135.0)$ \\
\hline $\mathrm{DBP}(\mathrm{mmHg})$ & $74.0(69.0-80.0)$ \\
\hline ESR $(\mathrm{mm} / \mathrm{hr})$ & $14.0(9.0-32.0)$ \\
\hline CRP (mg/L) & $0.6(0.6-0.8)$ \\
\hline \multicolumn{2}{|l|}{ Past history } \\
\hline Hypertension (n, \%) & $24(25.3)$ \\
\hline Diabetes mellitus (n, \%) & $10(10.5)$ \\
\hline \multicolumn{2}{|l|}{ Grip strength } \\
\hline Mean $^{a}$ & $20.0(16.5-24.5)$ \\
\hline Right & $20.0(16.0-25.0)$ \\
\hline Left & $22.0(16.0-25.0)$ \\
\hline \multicolumn{2}{|l|}{ Pinch strength } \\
\hline Mean $^{a}$ & $5.7(4.8-6.5)$ \\
\hline Right & $6.0(5.0-6.8)$ \\
\hline Left & $5.5(4.8-6.5)$ \\
\hline VAS pain & $34.0(20.0-52.0)$ \\
\hline $\mathrm{FIHOA}$ & $65.0(50.0-80.0)$ \\
\hline EQ-5D index & $0.82(0.77-0.87)$ \\
\hline EQ-VAS & $65.0(50.0-80.0)$ \\
\hline Total radiographic severity scores $(0-80)^{b}$ & $6.0(2.0-18.0)$ \\
\hline Number of affected joints $(0-20)^{b}$ & $5.0(2.0-9.0)$ \\
\hline
\end{tabular}

Data were described as median (Interquartile range) or number (\%) Abbreviation: $B M I$ body mass index; SBP systolic blood pressure; $D B P$ diastolic blood pressure; $E S R$ erythrocyte sedimentation rate; $C R P$ C-reactive protein: VAS visual analogue scale; FIHOA Functional Index for Hand Osteoarthritis; EQ$5 D$ EuroQol-5 dimension

${ }^{a}$ Average value of the sum of right and left hand scores

${ }^{\mathrm{b}}$ Based on Kellgren-Lawrence grade

\section{Comparison of variables according to FIHOA group}

There were no differences in age, sex, symptom duration, BMI, SBP, DBP, ESR, CRP, total radiographic severity score, and number of affected joints between the high and low FIHOA groups ( $p>0.05$ for all) (Table 2). Subjects with high FIHOA score had lower grip and pinch hand strength, higher patient VAS pain score, and lower EQ-5D index and EQ-VAS scores ( $p<0.05$ for all).

\section{Associations between FIHOA score and variables}

Analysis for variables related with FIHOA score showed that the score was negatively associated with mean grip and pinch hand muscle strengths, EQ-5D index, and EQ-VAS (Fig. 1). In contrast, FIHOA score was positively related with patient VAS pain. However, there were no relationships between FIHOA score and age, sex, symptom duration, BMI, SBP, DBP, ESR, CRP, total radiographic severity score, or number of affected joints.

\section{Variables associated with high FIHOA score}

Mean grip and pinch strength, patient VAS pain, EQ5D index, and EQ-VAS were associated with high FIHOA score in univariate regression analysis (Table 3). Multivariate regression analysis after adjusting for confounding factors of age, sex, and symptom duration revealed that high FIHOA score was significantly linked to patient VAS pain and EQ-5D index $(p=0.008$ and $p=0.013$, respectively).

\section{Discussion}

This study assessed the relationships of FIHOA score with other outcome measures including pain, grip and pinch hand strength, and EQ-5D in hand OA. In addition, correlation between functional impairment and radiographic damage was also explored. We found that FIHOA score was associated with patient-reported pain, hand strength, and quality of life based on the EQ-5D in hand OA. In addition, higher FIHOA score was associated with higher VAS pain score and lower EQ-5D index and EQ-VAS. However, there was no relationship between FIHOA score and radiographic outcome.

The outcome measures of hand OA include pain, hand physical function, and quality of life [3, 4]. Among the several hand OA-specific measures for physical disability that have been developed, such as the AUSCAN Index [5], the Cochin hand functional disability scale [6], and the FIHOA [7], FIHOA score is a unidimensional measure for functional impairment of hand OA and is considered a feasible and valid questionnaire commonly used in clinical study. Efforts have been made to verify the association between FIHOA score and other measures in OA. The Health Assessment Questionnaire (HAQ) [17], which is a rheumatoid arthritis-specific questionnaire for health status, was significantly associated with FIHOA score in hand OA $(r=0.73)$ and physical function scale of AUSCAN $(r=0.80)$ [18]. Similarly, EQ-5D, which is a generic measure for health-related quality of life [16], was also validated in patients with knee OA, showing a negative relationship of the Korean version of Western Ontario and McMaster Scale (KWOMAC) with the EQ-5D index [19]. There is a lack of data on the association between FIHOA score and EQ$5 \mathrm{D}$ in hand OA. As far as we know, this study is the first to find FIHOA score to be negatively related with EQ5D index and EQ-VAS, and patients with high FIHOA score showed a trend toward a lower EQ-5D index but not EQ-VAS in hand OA. Based on these observations, functional impairment might be linked to health-related quality of life in hand OA. 
Table 2 Comparison of variables according to FIHOA

\begin{tabular}{|c|c|c|c|}
\hline & FIHOA $\leq 4(n=49)$ & FIHOA > $4(n=46)$ & $p$ values \\
\hline Age (year) & $61.0(54.6-67.5)$ & $59.0(54.0-63.3)$ & 0.367 \\
\hline Sex, female $(n, \%)$ & $46(93.9)$ & $44(95.7)$ & 0.530 \\
\hline Symptom duration (month) & $24.0(1.0-96.0)$ & $4.0(1.0-30.0)$ & 0.120 \\
\hline BMI $\left(\mathrm{kg} / \mathrm{m}^{2}\right)$ & $23.4(21.3-24.0)$ & $23.8(21.5-25.9)$ & 0.295 \\
\hline SBP $(\mathrm{mmHg})$ & $126.0(114.0-135.0)$ & 127.5 (119.5-135.5) & 0.690 \\
\hline DBP (mmHg) & $74.0(69.0-80.0)$ & $75.5(69.5-80.3)$ & 0.463 \\
\hline ESR (mm/hr) & $14.0(9.0-27.3)$ & $14.0(8.0-20.5)$ & 0.376 \\
\hline CRP (mg/L) & $0.6(0.6-0.8)$ & $0.6(0.6-1.3)$ & 0.295 \\
\hline \multicolumn{4}{|l|}{ Grip strength } \\
\hline Mean $^{a}$ & $23.0(19.3-25.0)$ & $18.0(13.9-22.3)$ & $<0.001$ \\
\hline Right & $22.0(18.0-27.5)$ & $18.0(14.0-22.5)$ & 0.004 \\
\hline Left & $23.0(10.0-26.0)$ & $17.5(12.8-23.0)$ & $<0.001$ \\
\hline \multicolumn{4}{|l|}{ Pinch strength } \\
\hline Mean $^{a}$ & $6.3(5.3-7.1)$ & $5.4(4.0-6.4)$ & $<0.001$ \\
\hline Right & $6.3(5.1-7.3)$ & $5.5(3.5-6.5)$ & 0.001 \\
\hline Left & $6.0(5.0-7.0)$ & $5.5(3.9-6.0)$ & 0.002 \\
\hline VAS pain & $22.0(10.0-36.5)$ & $48.5(34.0-71.0)$ & $<0.001$ \\
\hline EQ-5D index & $0.87(0.82-0.91)$ & $0.82(0.7-0.86)$ & $<0.001$ \\
\hline EQ-VAS & $70.0(57.5-80.0)$ & $50.0(49.5-70.0)$ & $<0.001$ \\
\hline Total radiographic severity scores ${ }^{b}$ & $6.0(2.5-21.0)$ & $8.5(2.0-17.3)$ & 1.000 \\
\hline Number of affected joints ${ }^{\mathrm{b}}$ & $5.0(2.0-12.0)$ & $5.5(2.0-9.0)$ & 0.917 \\
\hline
\end{tabular}

Data were described as median (Interquartile range) or number (\%)

Abbreviation: $B M I$ body mass index; SBP systolic blood pressure; DBP diastolic blood pressure; ESR erythrocyte sedimentation rate; CRP C-reactive protein; VAS visual analogue scale; FIHOA Functional Index for Hand Osteoarthritis; EQ-5D EuroOol-5 dimensio

${ }^{a}$ Average value of the sum of right and left hand scores

${ }^{b}$ Based on Kellgren-Lawrence grade

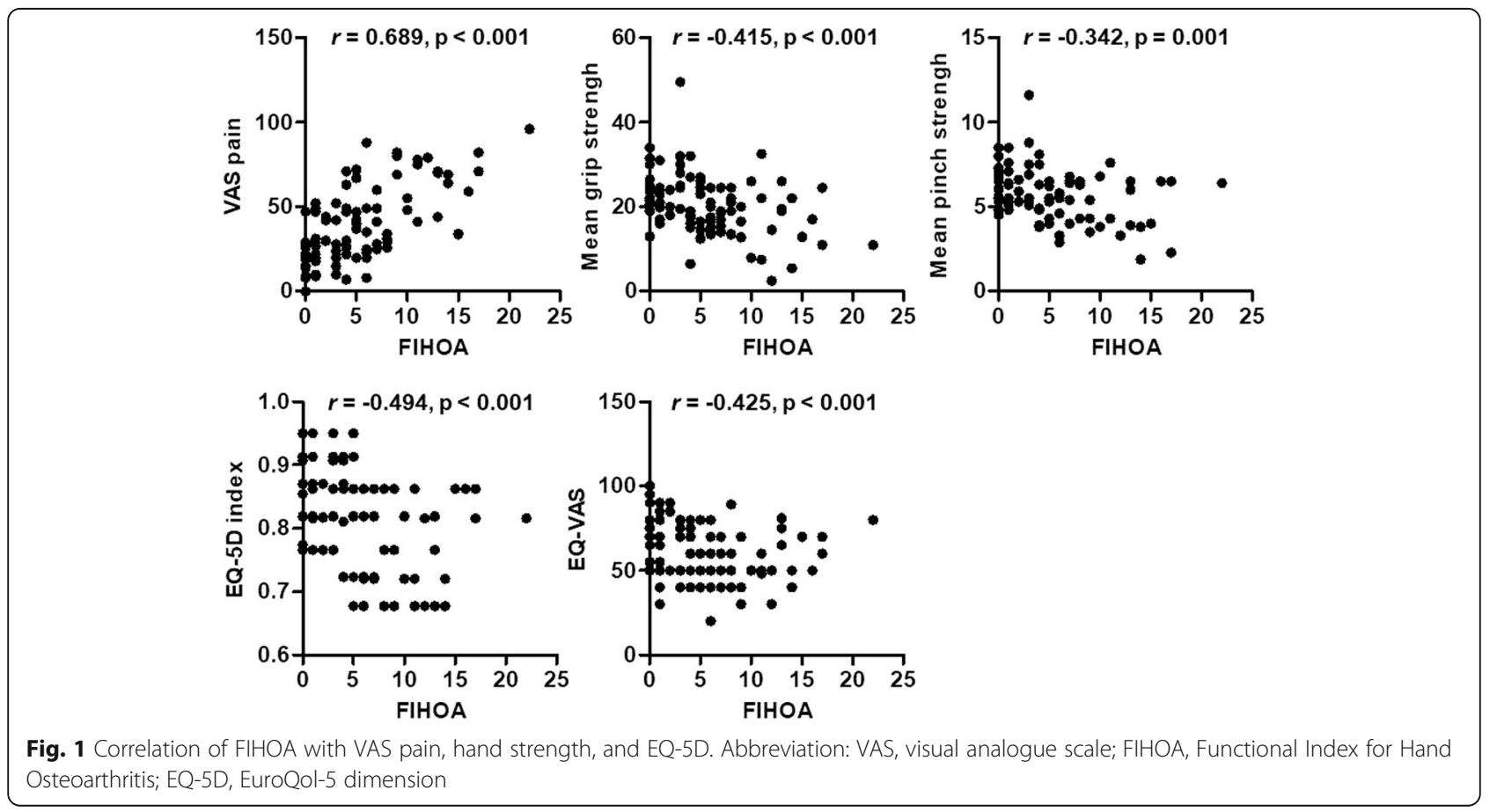


Table 3 Determination of variables related with high FIHOA score

\begin{tabular}{|c|c|c|c|c|c|c|}
\hline \multirow[b]{2}{*}{ Variables } & \multicolumn{3}{|c|}{ Univariate regression } & \multicolumn{3}{|c|}{ Multivariate regression } \\
\hline & $\overline{\mathrm{OR}}$ & $95 \% \mathrm{Cl}$ & $p$ values & $\overline{\text { OR }}$ & $95 \% \mathrm{Cl}$ & $p$ values \\
\hline Age (year) & 0.978 & $0.934-1.025$ & 0.362 & 0.940 & $0.864-1.022$ & 0.149 \\
\hline Sex, female $(n, \%)$ & 0.697 & $0.111-4.372$ & 0.700 & 1.919 & $0.128-28.793$ & 0.637 \\
\hline Symptom duration (month) & 0.995 & $0.988-1.001$ & 0.111 & 0.988 & $0.976-1.001$ & 0.078 \\
\hline BMI $\left(\mathrm{kg} / \mathrm{m}^{2}\right)$ & 1.060 & $0.900-1.226$ & 0.535 & & & \\
\hline ESR (mm/hr) & 0.974 & $0.939-1.009$ & 0.146 & & & \\
\hline CRP (mg/L) & 1.137 & $0.856-1.512$ & 0.375 & & & \\
\hline Mean grip strength & 0.871 & $0.803-0.945$ & 0.001 & 0.907 & $0.794-1.037$ & 0.152 \\
\hline Mean pinch strength & 0.525 & $0.368-0.748$ & $<0.001$ & 0.803 & $0.445-1.448$ & 0.466 \\
\hline Patient VAS & 1.066 & $1.038-1.096$ & $<0.001$ & 1.044 & $1.011-1.079$ & 0.008 \\
\hline EQ-5D index & 0.000 & $0.000-0.001$ & $<0.001$ & 0.000 & $0.000-0.069$ & 0.013 \\
\hline EQ-VAS & 0.947 & $0.921-0.974$ & $<0.001$ & 0.970 & $0.931-1.011$ & 0.149 \\
\hline Total radiographic severity scores & 0.996 & $0.963-1.030$ & 0.815 & & & \\
\hline Number of affected joints & 0.988 & $0.913-1.070$ & 0.773 & & & \\
\hline
\end{tabular}

Abbreviation: $B M I$ body mass index; $E S R$ erythrocyte sedimentation rate; CRP C-reactive protein; VAS visual analogue scale; EQ-5D EuroQol-5 dimension

It has been previously demonstrated that FIHOA score was relatively well associated with radiographic damages in hand OA $[9,10,20,21]$. In assessment of correlation between hand functional limitation by AUSCAN function and FIHOA score and radiographic damage, FIHOA score was better correlated with radiographic structural changes than was the AUSCAN index [21]. FIHOA scores revealed larger physical disability in patients with erosive OA compared to those with non-erosive hand OA [20]. In addition, number of radiographic remodeled joints was markedly associated with FIHOA score in erosive OA. Number of joints with radiographic damage was shown to be a predictor of functional impairment $(\beta=0.54,95 \% \mathrm{CI}$ $0.24-0.84, p<0.01$ ). Compatible with these studies, radiographic severity determined by the Kellgren-Lawrence scale was significantly associated with FIHOA score [9, 10]. However, this study observed lack of association between radiographic outcomes such as total radiographic severity score and number of affected joints and FIHOA score. Similarly, Roux et al. showed that FIHOA score was not associated with number of OA joints with $\mathrm{K}-\mathrm{L}$ grade $\geq 2$, Verbruggen score, or osteophytes in Kallman score [10]. Ultrasound is a musculoskeletal imaging tool with many advantages over radiography in reliable and reproducible detection of intra- and extra-articular structural abnormalities, such as joint effusion, synovitis, bone erosions, and therapeutic monitoring in arthritis [22]. There is a close relationship between radiographic features and ultrasound findings [23]. However, FIHOA and AUSCAN scores were not associated with ultrasound findings $[11,24]$. Important clinical questions about the relationship between functional impairment and diverse imaging tests, including conventional radiography, should be confirmed in large studies.
The VAS pain scale is frequently used to assess patient-reported pain in OA. Some studies have investigated whether physical function measures such as FIHOA and AUSCAN indexes are associated with VAS pain $[11,18]$. A cross-sectional study revealed that FIHOA score was significantly associated with VAS pain and AUSCAN pain subscale $(r=0.51$ and $r=0.79$, respectively) [18]. It has been reported that tenderness on palpation was significantly related to FIHOA score [11]. Consistently, our study confirmed a close correlation between FIHOA score and VAS pain. In addition, high FIHOA score was positively dependent on VAS pain. This suggests that FIHOA score reflects to some extent the pain in hand OA patients, although this relationship should be validated in a larger study population.

Performance-based physical function tools such as pinch and grip strength for measurement of physical function of hands have been used in clinical studies of hand OA [25]. Substantial evidence of a negative association of grip or pinch strength with AUSCAN function subscale has been noted $[5,18,26]$. Interestingly, Moe et al. demonstrated a negative relationship between mean grip strength and FIHOA score $(r=-0.58)$ [18]. Compatible with earlier data, the present study also found significant negative association between FIHOA score and two hand strength measures. This provides adequate evidence that there is comparable equivalence between questionnaire- and performance-based instruments in evaluating physical function of hand $\mathrm{OA}$ patients.

There are some limitations in this study. First, the results of this study originated from cross-sectional observation. Analysis of the causal relationships between FIHOA scores and clinical features, hand strength, and 
radiologic findings is needed in prospective studies. Second, the patient reported FIHOA index does not evaluate the relevance of AUSCAN function subscale and Cochin hand function scale. The clinical, physical, and radiographic measures related to FIHOA score in hand $\mathrm{OA}$ need to be verified using other hand function tools such as AUSCAN and Cochin hand function scale. In addition, most of the patients in this study consisted of women. Women have higher incidence and prevalence of knee, hand, feet OA than men [27]. Especially, decreased sex hormone contributes to an increased hand OA in female [28]. Musculoskeletal function and pain in knee OA was known to be dependent on gender [29]. This suggests that pain, functional impairment and quality of life in hand OA might be different between men and women. It is necessary to evaluate whether there is gender difference of functional outcome measures such as FIHOA.

\section{Conclusion}

This is the first observation that FIHOA score, an index for questionnaire-based physical function, is associated with EQ-5D, VAS pain, and grip and pinch strength in hand OA but not with radiographic changes. Longitudinal prospective analyses are needed to evaluate whether changes in FIHOA score are linked to those in other measures in hand OA.

\section{Acknowledgements \\ None.}

\section{Disclosure statement}

The authors do not have an actual or potential conflict of interest or not get interest of any kind to declare with regard to this work.

\section{Authors' contributions}

SK, UHJ, and JC contributed the conception and design of the study. SK and UHJ participated in data collection. SK and JC provided substantial supervision and interpretation of the statistical analysis. SK drafted and revised the manuscript. All authors have critically read this manuscript and approved the final version.

\section{Funding}

None.

\section{Availability of data and materials}

not applicable.

\section{Declarations}

Ethics approval and consent to participate

The Institutional Review Board approved this study (CR-20-139-L). The informed consent of all patients was waived because this study was performed by a retrospective analysis.

\section{Consent for publication}

not applicable.

\section{Competing interests}

The authors declare that they have no competing interests.
Received: 5 October 2020 Accepted: 8 March 2021

Published online: 19 March 2021

\section{References}

1. Marshall M, Watt FE, Vincent TL, Dziedzic K. Hand osteoarthritis: clinical phenotypes, molecular mechanisms and disease management. Nat Rev Rheumatol. 2018;14(11):641-56. https://doi.org/10.1038/s41584-018-0095-4.

2. Zhang W, Doherty M, Leeb BF, Alekseeva L, Arden NK, Bijlsma JW, Dincer F, Dziedzic K, Hauselmann HJ, Kaklamanis P, Kloppenburg M, Lohmander LS, Maheu E, Martin-Mola E, Pavelka K, Punzi L, Reiter S, Smolen J, Verbruggen G, Watt I, Zimmermann-Gorska I, ESCISIT. EULAR evidence-based recommendations for the diagnosis of hand osteoarthritis: report of a task force of ESCISIT. Ann Rheum Dis. 2009;68(1):8-17. https://doi.org/10.1136/a rd.2007.084772.

3. Bellamy N, Kirwan J, Boers M, Brooks P, Strand V, Tugwell P, et al. Recommendations for a core set of outcome measures for future phrase III clinical trials in knee, hip and hand osteoarthritis. Consensus development at OMERACT III. J Rheumatol. 1997;24:799-802.

4. Maheu E, Altman RD, Bloch DA, Doherty M, Hochberg M, Mannoni A, Punzi L, Spector T, Verbruggen G, Osteoarthritis Research Society International Hand OA Task Force, Carr A, Cicuttini F, Dreiser RL, Haraoui BP, Hart D, Pelletier J, Ramonda R, Rovati L. Design and conduct of clinical trials in patients with osteoarthritis of the hand: recommendations from a task force of the osteoarthritis research society international. Osteoarthr Cartil. 2006; 14(4):303-22. https://doi.org/10.1016/j.joca.2006.02.010.

5. Bellamy N, Campbell J, Haraoui B, Gerecz-Simon E, Buchbinder R, Hobby K, MacDermid JC. Clinimetric properties of the AUSCAN osteoarthritis hand index: an evaluation of reliability, validity and responsiveness. Osteoarthr Cartil. 2002;10(11):863-9. https://doi.org/10.1053/joca.2002.0838.

6. Duruöz MT, Poiraudeau S, Fermanian J, Menkes CJ, Amor B, Dougados M, et al. Development and validation of a rheumatoid hand functional disability scale that assesses functional handicap. J Rheumatol. 1996;23: 1167-72.

7. Dreiser RL, Maheu E, Guillou GB, Caspard H, Grouin JM. Validation of an algofunctional index for osteoarthritis of the hand. Rev Rhum Engl Ed. 1995; 62(Suppl 1):43S-53S

8. Dreiser RL, Maheu E, Guillou GB. Sensitivity to change of the functional index for hand osteoarthritis. Osteoarthritis Cartilage. 2000;8(Suppl A):S25-8.

9. Bagis S, Sahin G, Yapici Y, Bolgen Cimen O, Erdogan C. The effect of hand osteoarthritis on grip and pinch strength and hand function in postmenopausal women. Clin Rheumatol. 2003;22(6):420-4. https://doi.org/10.1 007/s10067-003-0792-4.

10. Roux CH, Foltz V, Maheu E, Baron G, Gandjbakhch F, Lukas C, Wendling D, Loeuille D, Lafforgue P, Euler-Ziegler L, Richette P, Chevalier X, French Section on Osteoarthritis. MRI and serum biomarkers correlate with radiographic features in painful hand osteoarthritis. Clin Exp Rheumatol. 2016;34(6):991-8.

11. Koutroumpas AC, Alexiou IS, Vlychou M, Sakkas LI. Comparison between clinical and ultrasonographic assessment in patients with erosive osteoarthritis of the hands. Clin Rheumatol. 2010;29(5):511-6. https://doi. org/10.1007/s10067-009-1348-z.

12. Haugen IK, Bøyesen P, Slatkowsky-Christensen B, Sesseng S, van der Heijde D, Kvien TK. Associations between MRI-defined synovitis, bone marrow lesions and structural features and measures of pain and physical function in hand osteoarthritis. Ann Rheum Dis. 2012;71(6):899-904. https://doi.org/1 0.1136/annrheumdis-2011-200341.

13. Altman R, Alarcón $G$, Appelrouth D, Bloch D, Borenstein D, Brandt $K$, et al. The American College of Rheumatology criteria for the classification and reporting of osteoarthritis of the hand. Arthritis Rheum. 1990;33(11):1601-10. https://doi.org/10.1002/art.1780331101.

14. Kellgren JH, Lawrence JS. Radiological assessment of osteoarthrosis. Ann Rheum Dis. 1957;16(4):494-502. https://doi.org/10.1136/ard.16.4.494.

15. Ahn GY, Cho SK, Cha SJ, Nam E, Lee JE, Dreiser RL, Maheu E, Sung YK. Cross-cultural adaptation and validation of the Korean version of the functional index for hand osteoarthritis (FIHOA). Int J Rheum Dis. 2018; 21(12):2095-103. https://doi.org/10.1111/1756-185X.13412.

16. Kim MH, Cho YS, Uhm WS, Kim S, Bae SC. Cross-cultural adaptation and validation of the Korean version of the EQ-5D in patients with rheumatic diseases. Qual Life Res. 2005;14(5):1401-6. https://doi.org/10.1007/s11136004-5681-z. 
17. Fries JF, Spitz P, Kraines RG, Holman HR. Measurement of patient outcome in arthritis. Arthritis Rheum. 1980;23(2):137-45. https://doi.org/10.1002/art.1 780230202.

18. Moe R, Garratt A, Slatkowsky-Christensen B, Maheu E, Mowinckel P, Kvien T, et al. Concurrent evaluation of data quality, reliability and validity of the Australian/Canadian osteoarthritis hand index and the functional index for hand osteoarthritis. Rheumatology (Oxford). 2010;49(12):2327-36. https://doi. org/10.1093/rheumatology/keq219.

19. Lim NY, Lee I, Lee EN, Lee KS, Cho KS, Rhee S, et al. A validation study of EQ-5D in the patients with osteoarthritis. J Muscle Joint Health. 2010;17(2): 203-11. https://doi.org/10.5953/JMJH.2010.17.2.203.

20. Wittoek R, Cruyssen BV, Verbruggen G. Predictors of functional impairment and pain in erosive osteoarthritis of the interphalangeal joints: comparison with controlled inflammatory arthritis. Arthritis Rheum. 2012;64(5):1430-6. https://doi.org/10.1002/art.33502.

21. Wittoek R, Verbruggen G. Correlation between FIHOA and AUSCAN and radiographic damage in patients with osteoarthritis of the hands. Osteoarthritis Cartilage. 2008;16(Suppl 4):S114.

22. McNally EG. Ultrasound of the small joints of the hands and feet: current status. Skelet Radiol. 2008;37(2):99-113. https://doi.org/10.1007/s00256-0070356-9.

23. Oo WM, Deveza LA, Duong V, Fu K, Linklater JM, Riordan EA, Robbins SR, Hunter DJ. Musculoskeletal ultrasound in symptomatic thumb-base osteoarthritis: clinical, functional, radiological and muscle strength associations. BMC Musculoskelet Disord. 2019;20(1):220. https://doi.org/10.11 86/s12891-019-2610-4.

24. Keen HI, Wakefield RJ, Grainger AJ, Hensor EM, Emery P, Conaghan PG. An ultrasonographic study of osteoarthritis of the hand: synovitis and its relationship to structural pathology and symptoms. Arthritis Rheum. 2008; 59(12):1756-63. https://doi.org/10.1002/art.24312.

25. Visser AW, Bøyesen P, Haugen IK, Schoones JW, van der Heijde DM, Rosendaal FR, Kloppenburg M. Instruments measuring pain, physical function, or Patient's global assessment in hand osteoarthritis: a systematic literature search. J Rheumatol. 2015;42(11):2118-34. https://doi.org/10.3899/ jrheum.141228.

26. Allen $\mathrm{KD}$, Jordan JM, Renner JB, Kraus VB. Validity, factor structure, and clinical relevance of the AUSCAN osteoarthritis hand index. Arthritis Rheum. 2006;54(2):551-6. https://doi.org/10.1002/art.21615.

27. Srikanth VK, Fryer JL, Zhai G, Winzenberg TM, Hosmer D, Jones G. A metaanalysis of sex differences prevalence, incidence and severity of osteoarthritis. Osteoarthr Cartil. 2005;13(9):769-81. https://doi.org/10.1016/j. joca.2005.04.014

28. Sowers MF, Hochberg M, Crabbe JP, Muhich A, Crutchfield M, Updike S. Association of bone mineral density and sex hormone levels with osteoarthritis of the hand and knee in premenopausal women. Am J Epidemiol. 1996;143(1):38-47. https://doi.org/10.1093/oxfordjournals.aje.a 008655

29. Phinyomark A, Osis ST, Hettinga BA, Kobsar D, Ferber R. Gender differences in gait kinematics for patients with knee osteoarthritis. BMC Musculoskelet Disord. 2016;17(1):157. https://doi.org/10.1186/s12891-016-1013-z.

\section{Publisher's Note}

Springer Nature remains neutral with regard to jurisdictional claims in published maps and institutional affiliations.

\section{Ready to submit your research? Choose BMC and benefit from:}

- fast, convenient online submission

- thorough peer review by experienced researchers in your field

- rapid publication on acceptance

- support for research data, including large and complex data types

- gold Open Access which fosters wider collaboration and increased citations

- maximum visibility for your research: over $100 \mathrm{M}$ website views per year

At BMC, research is always in progress.

Learn more biomedcentral.com/submissions 